\title{
Sanrachna
}

\section{$\underline{\text { Impact of Climate Change on Vector Borne Diseases (VBD) }}$}

\begin{abstract}
Temporal and spatial changes in weather that are expected to occur under different climate change scenarios will affect the biology and ecology of vectors and the risk of disease transmission. It is estimated that average global temperature will have risen by 1.0-3.5 degree Celsius by 2100, increasing the likelihood of many vector borne diseases. This study aims at reviewing temporal and spatial changes in the climate and vector-borne diseases in India. The weather data is collected from IBM weather API for Himachal Pradesh and Uttar Pradesh. Changing temperature (including Himalayas hills regions), rain intensity, prolonged monsoon creates a favourable breeding condition for vector. One of the vectors borne disease Japanese encephalitis is still a major health problem in five districts in Eastern UP (Gorakhpur, Kushinagar, Maharajganj, Sant Kabir Nagar and Siddarth Nagar), these regions are the most affected by floods from rivers originating in the Nepali hills. Himalayan hills region of Nepal also affected by global warming. In that way, Climate change is a big factor in the transmission of vector-borne diseases.
\end{abstract}

Keywords: vector borne diseases, climate change, precipitation, temperature

\section{Introduction}

Climate change refers to any change in weather patterns like change in surface temperature, precipitation, humidity and poor air quality etc. It may be due to natural causes or human causes. Modelling studies have suggested that climate change has favoured and will continue to favour dengue transmission. Over the years there has been reduction in the incidence of vector borne diseases, but the issue of climate change has put a threat on containing mosquitoes' breeding. Vector borne diseases (VBD) are the infectious diseases which are transmitted to humans from vectors such as mosquito, ticks ad flies. Dengue transmission is still prevalent in regions where malaria has been controlled or eradicated. Increased rainfall, 


\section{Sanrachna}

humidity and temperature creates more suitable conditions for vector breeding to occur more quickly as eggs hatches faster in hotter climates. Non-climatic factors such as increase in urbanization, international trade and travel also contribute to the emergence of vector borne diseases.

As per the WHO estimates, 228 million cases of malaria occurred globally in 2018 with 405000 deaths. Nineteen countries in sub-Saharan Africa and India carried almost 85 percent of the global burden from malaria. Vectors cannot regulate their body temperature and need external warmth to survive. Increase in temperature may cause vector range patterns to shift, increasing the risk to new population. Humidity and stagnant water are crucial for vector breeding. In India there are nine major vectors of malaria of which An. culicifacies, An. fluviatilis, An. stephensi, An. minimus and An. dirus are the primary vectors in India, while An. sundaicus, An. annularis, An. pulcherrimus and An. subpictus are reported as the secondary vectors.

Since 1990s, dengue has become more frequent in India especially in urban zones and they also spread to new geographic regions. This geographic expansion is due to changes in ecoclimatic factors, climate change, rapid urbanization, population growth and population movement. India alone contributes about 34 percent global dengue burden and two-third of India's population are estimated to be at risk of dengue infection. WHO estimates that onesixth of the illness and disability suffered globally is due to vector borne diseases. The burden of climate sensitive diseases is greatest for the poorest population.

\section{Temporal and spatial climate change:}

As per the Indian Network of Climate Change Assessment (INCAA) report, the four regions that are vulnerable to climate change by the year 2030 are Himalayan region, North-eastern states, Western Ghats and coastal regions. The effect of climate change on transmission of vector borne diseases is likely to be observed at the extremes of the range of temperatures at which transmission occurs. For many diseases these lies in the range 14-18 degree Celsius at the lower end and 35-40 degree Celsius at the upper end. 


\section{Sanrachna}

In Himachal Pradesh, there has been a change in weather pattern. The monsoon sets early and withdraws late, prolonging the season. In June and September, it get 10-15 percent more rainfall whereas 60-70 percent rainfall happens in July and August.

In our study we have analysed the temporal weather changes in Himachal Pradesh and Uttar Pradesh for the period 2016-2019 (July to September). The parameters we have looked are temperature, relative humidity $(\mathrm{RH})$ and precipitation $24 \mathrm{hr}$. There found changes in the pattern of these three parameters over the studied period. Relative humidity is the ratio of amount of water vapour present in the air to the amount of water vapour that could be at a given temperature. Precipitation is the condensation of atmospheric water vapour that falls from cloud in the form of drizzle, rain, sleet, snow ad hails.

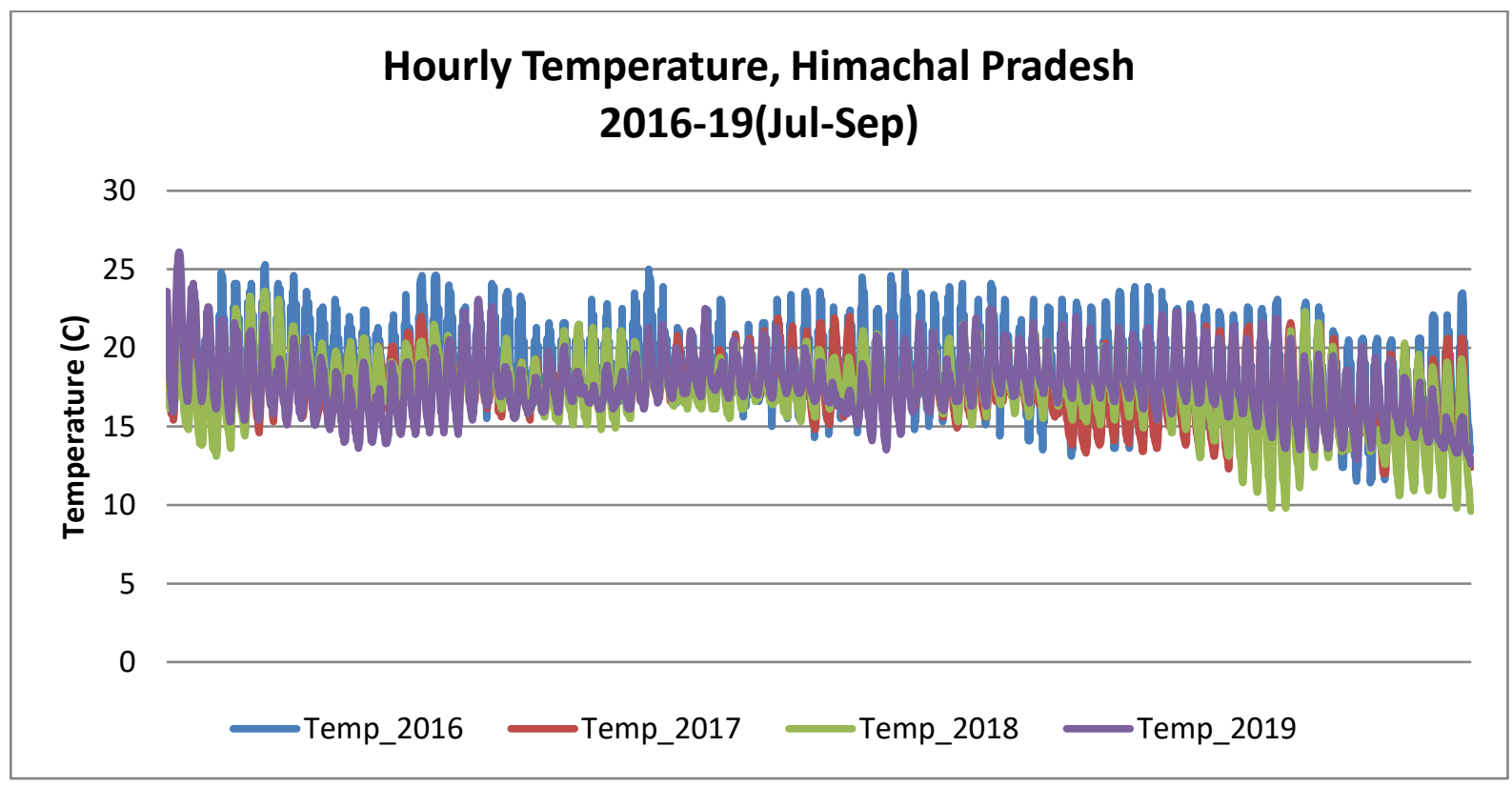

Figure1. Temperature, Himachal Pradesh

Temperature levels in 2019 were low as compared to the year 2016, but mostly higher than the year 2017 and 2018. 


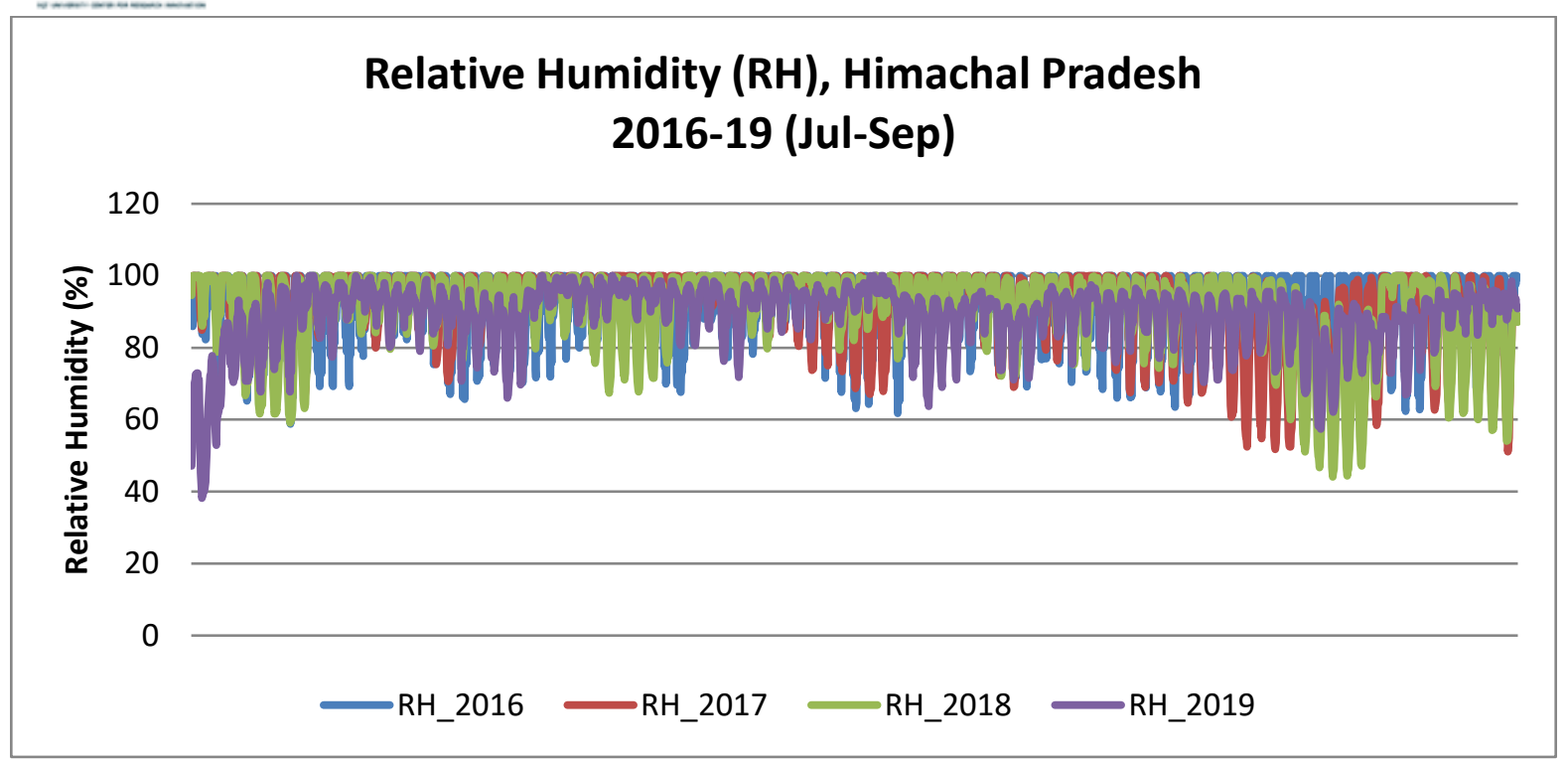

Figure 2. Relative Humidity, Himachal Pradesh

Relative humidity was high in the year 2018 ad 2019 as compared to the previous years. Higher humidity creates ideal conditions for mosquitoes to thrive.



Figure 3. Precipitation, Himachal Pradesh

Precipitation rate was high in the year 2018 most of the time as compared to the year 2019. The year 2019 has the least precipitation as compared to the previous years. It can be said that the pattern of rainfall in Himachal Pradesh is changing. 


\section{Sanrachna}

In Uttar Pradesh, uneven patterns of temperature and precipitation were found, but there was high humidity is in the year 2019 as compared to the previous years. In the year 2018, at some point of times the precipitation level reached above 100 .

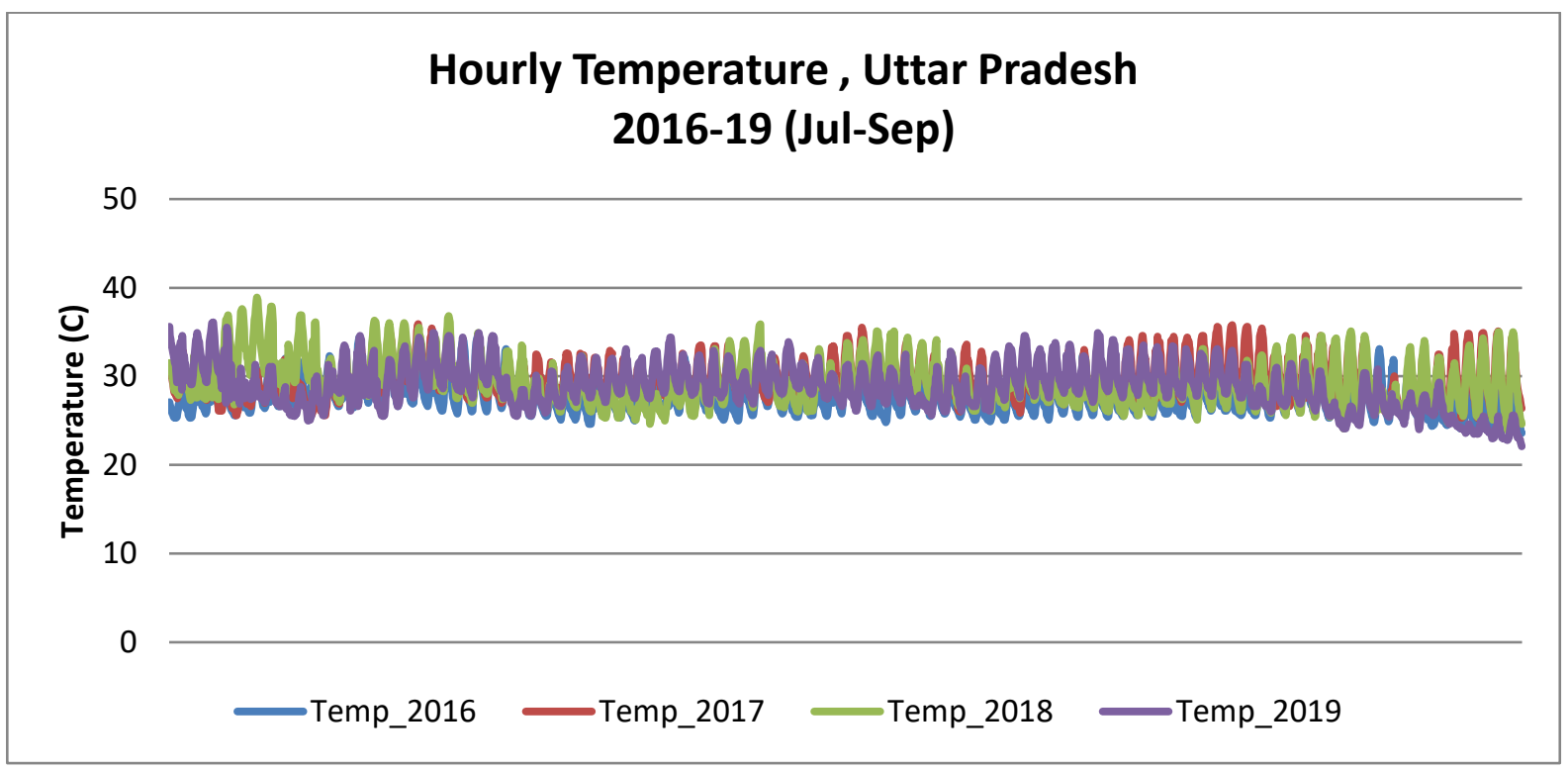

Figure 4. Temperature, Uttar Pradesh

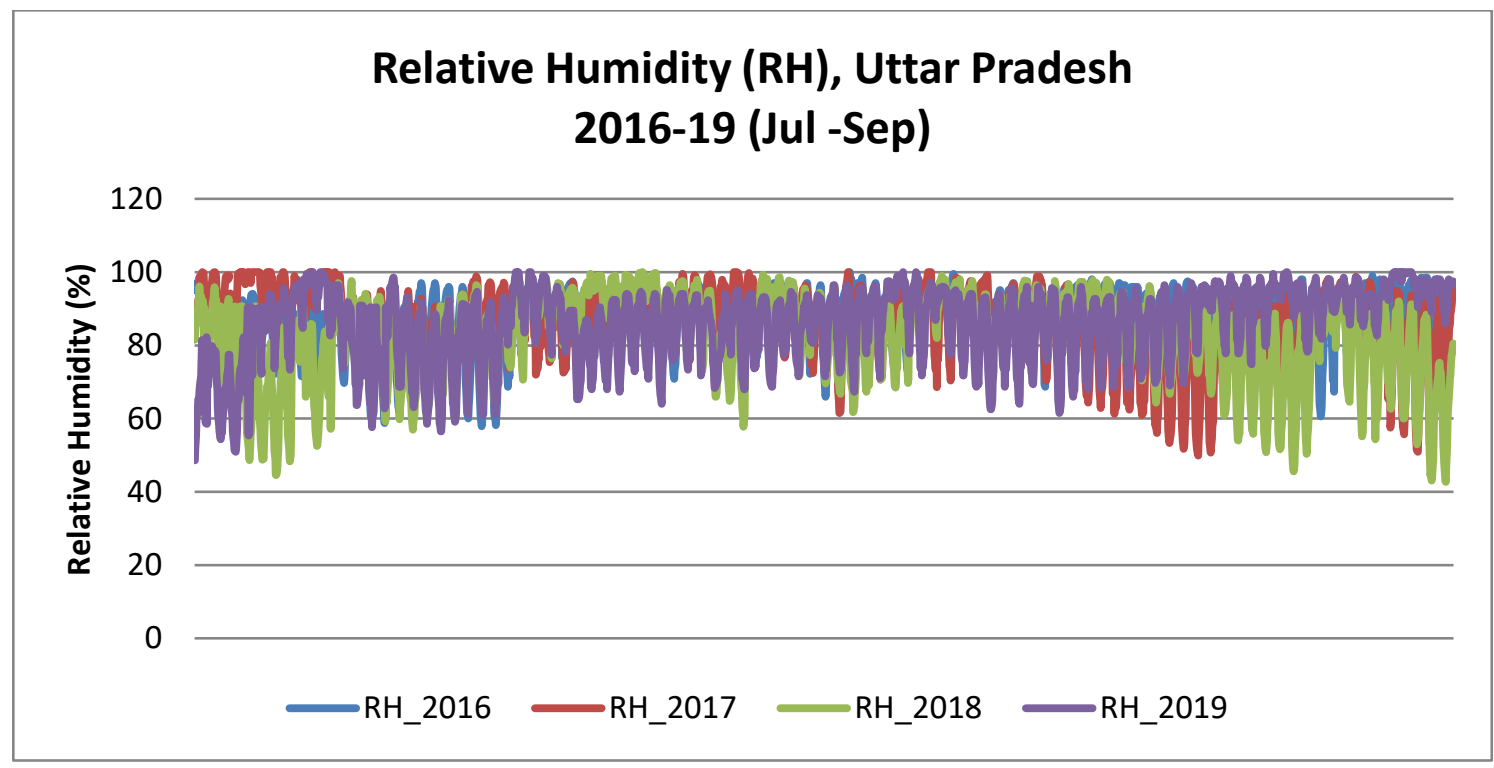

Figure 5. Relative Humidity, Uttar Pradesh 
Sanrachna

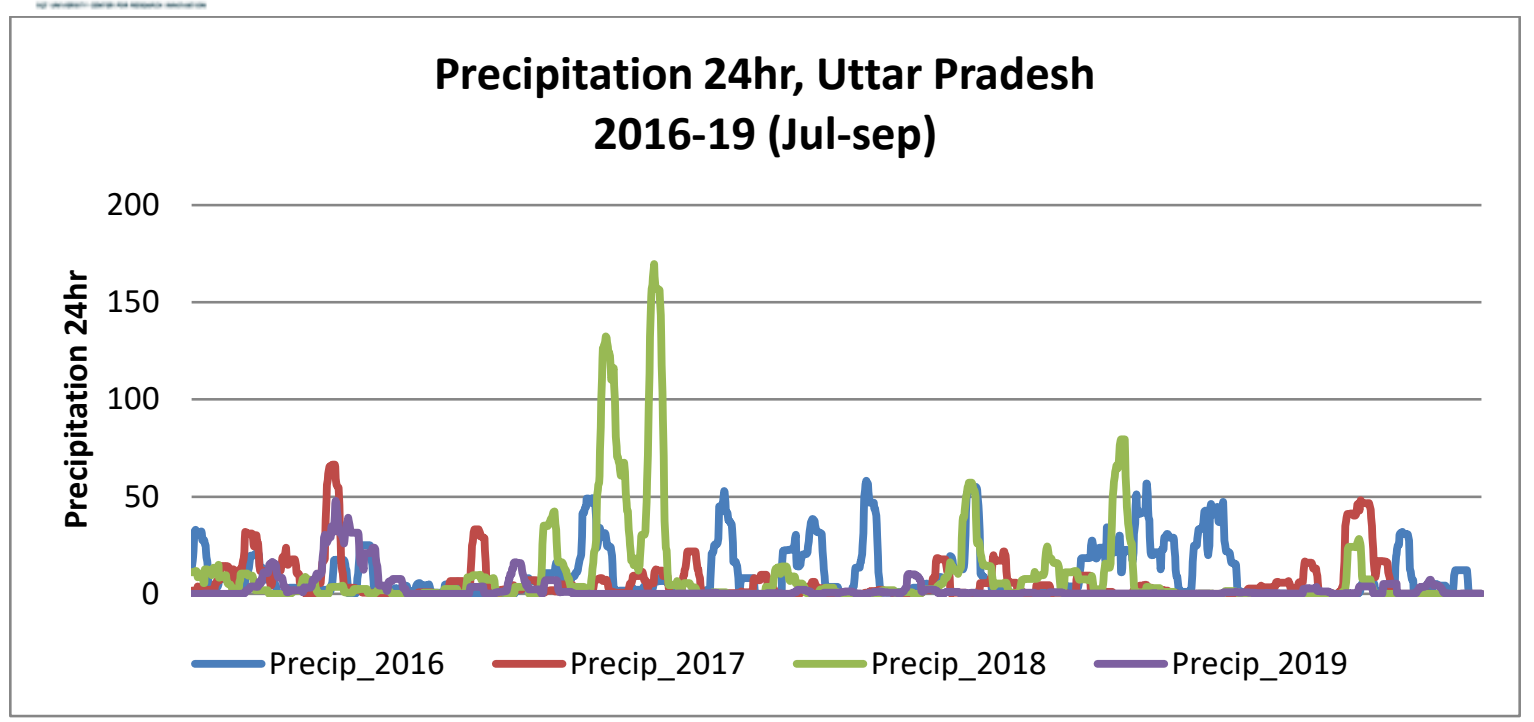

Figure 6. Precipitation 24hr, Uttar Pradesh

\section{Spatial and Temporal Changes in Malaria}

Statistical and visualization tool Python is used to map the spatial distribution of malaria cases in India. There is a shift in higher number of cases of malaria from Odisha to Uttar Pradesh.
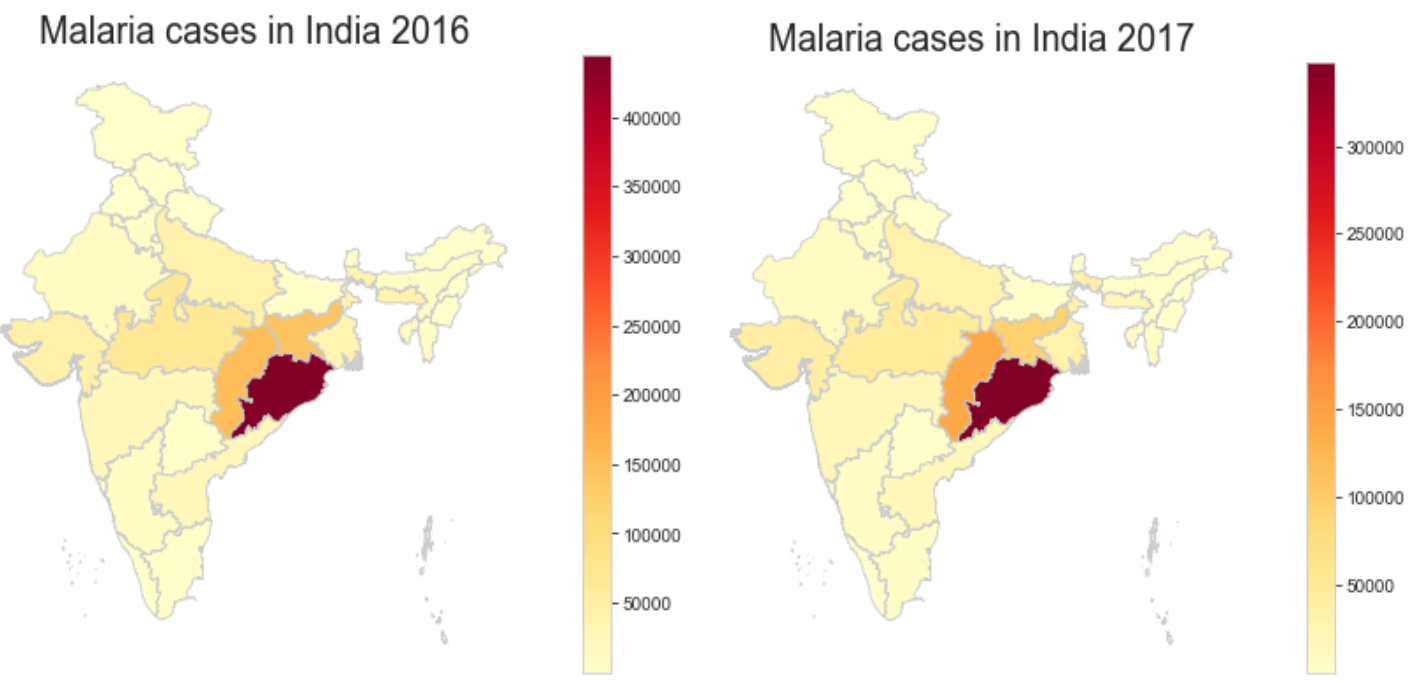


\section{Sanrachna}

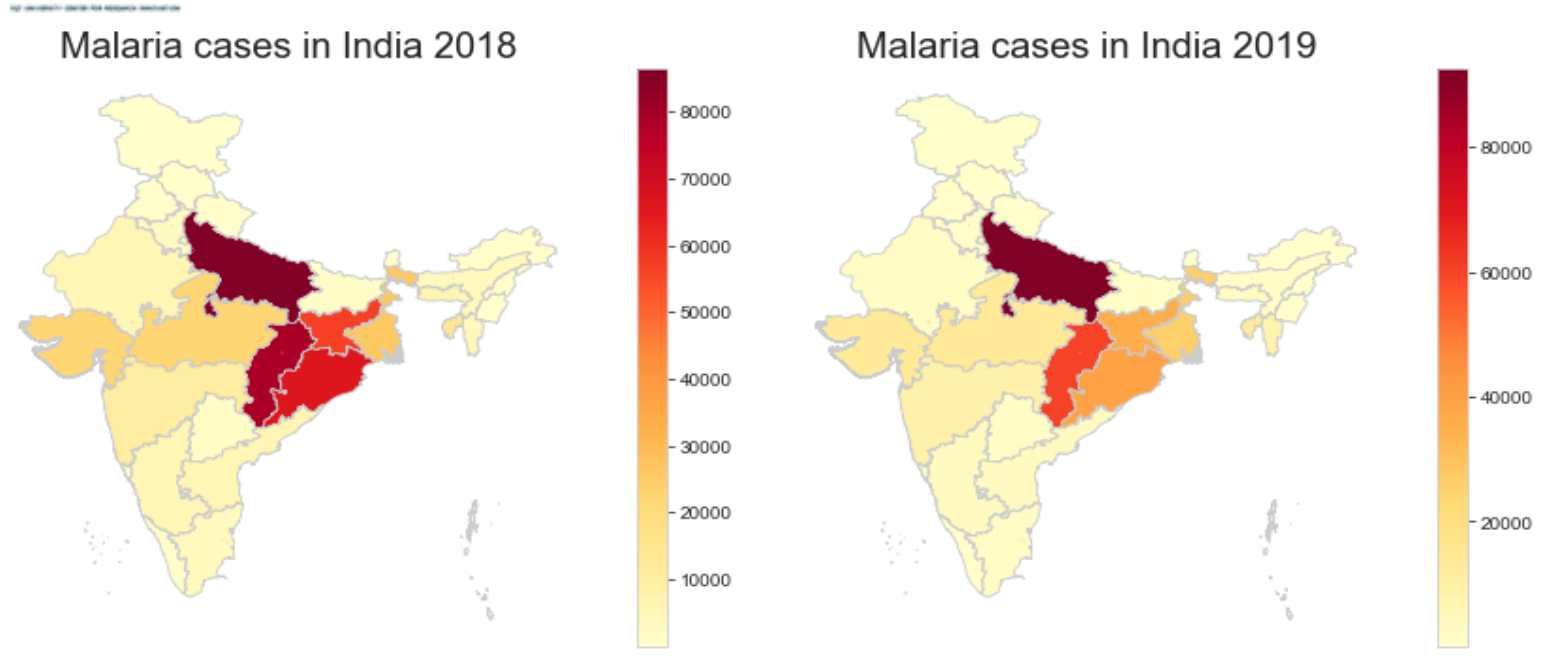

Highest cases of malaria:

- 2016: Odisha (444843)

- 2017: Odisha (347860)

- 2018: Uttar Pradesh (86486)

- 2019: Uttar Pradesh (92732)

\begin{tabular}{|l|l|l|l|l|}
\hline States & $\mathbf{2 0 1 6}$ & $\mathbf{2 0 1 7}$ & $\mathbf{2 0 1 8}$ & $\mathbf{2 0 1 9}$ \\
\hline Chhattisgarh & 148220 & 140727 & 78717 & 60575 \\
\hline Himachal Pradesh & 106 & 96 & 98 & 109 \\
\hline Manipur & 122 & 80 & 12 & 15 \\
\hline Odisha & 444843 & 347860 & 66311 & 39557 \\
\hline Punjab & 693 & 805 & 624 & 1143 \\
\hline Uttar Pradesh & 40700 & 3235 & 86486 & 92732 \\
\hline Delhi & 31 & 577 & 473 & 713 \\
\hline Lakshadweep & 2 & 1 & 5 & 11 \\
\hline
\end{tabular}

Table 1. Climate Change and Cases of Malaria

Source: National Vector Borne Disease Control Programme (NVDCP)

The table is showing the number of cases of malaria from 2016 to 2019 for the selected states of India. The highlighted figures with red are for the states which saw rise in malaria cases in 2019. States located at high altitudes are also facing the problem of vector borne diseases. This is due to climate change. Global climate change is likely to alter the spatial and temporal distribution of vector borne diseases. 


\section{Sanrachna}

\section{Conclusion}

Last few decades show that climate change affects rain pattern, temperature and the time spam of rainy season. Due to heavy rainfall and prolonged monsoon with increase in the humidity, vector-borne diseases expand its geographical area from Gangetic plains to foothills of the Himalayas. Relative humidity in Himachal Pradesh is found high in the year 2018 and 2019 for the month July to September. Precipitation rate was also high in the year 2018. While in Uttar Pradesh uneven patterns of temperature and precipitation were found, but there was high humidity is in the year 2019 as compared to the previous years. In the year 2018, at some point of time the precipitation level reached above 100. In the Eastern part of Uttar Pradesh, humid condition increases due to water logging for paddy field cultivation, this water logging field provide suitable condition like chikungunya, filariasis, and Japanese encephalitis. Although increasing in vector-borne disease is the impact of climate change but only climate change is not the main reason. There are more other factors like lack of awareness, unhygienic water storage in house, lack of sanitation and lack of technical support in agriculture increases threat and challenges for the future generation. 


\section{Sanrachna}

\section{Reference}

Climate Risk and Spread of Vector-Borne Diseases. (n.d.). Retrieved from climatenexus:

https://climatenexus.org/climate-issues/health/climate-change-and-vector-borne-diseases/

Dhiman, R. C., Pahwa, S., Dhillon, G. P., \& Dash, A. P. (2010). Climate change and threat of vectorborne diseases in India: Are we prepared? Parasitology Research. ResearchGate.

Githeko, A. K., Lindsay, S. W., Confalonieri, U. E., \& Patz, J. A. (2000). Climate change and vectorborne diseases: a regional analysis. World Health Organization (WHO).

Kakarla, S. G., Caminade, C., Mutheneni, S. R., Morse, A. P., Upadhyayula, S. M., Kadiri, M. R., et al. (2019). Lag effect of climatic variables on dengue burden in India. Epidemiology \& Infection .

Lendrum, C. D., Manga, L., Bagayoko, M., \& Sommerfeld, J. (2015). Climate change and vector-borne diseases: what are the implications for public health research and policy? Philos Trans $R$ Soc Lond $B$ Biol Sci.

Ray, K. (2018). Dengue outbreak in Himachal points to climate change? DECCANHERALD.

Sarkar, S., Gangare, V., Singh, P., \& Dhiman, R. C. (2019). Shift in Potential Malaria Transmission Areas in India, Using the Fuzzy-Based Climate Suitability Malaria Transmission (FCSMT) Model under Changing Climatic Conditions. IJERPH .

(2019). The "world malaria report 2019" at a glance. World Health Organization (WHO). 